\title{
In vitro gas and short-chain fatty acid production from soybean meal treated with chestnut and quebracho wood extracts by using sheep rumen fluid
}

\author{
A. Lavrenčič ${ }^{1}$ and T. Pirman \\ University of Ljubljana, Biotechnical Faculty, Department of Animal Sciences, Groblje 3, SI-1230 Domžale, Slovenia
}

KEY WORDS: chestnut, in vitro gas production, quebracho, short-chain fatty acids, tannins

Received: 18 August 2021

Revised: 3 November 2021

Accepted: 6 December 2021

${ }^{1}$ Corresponding author:

e-mail: andrej.lavrencic@bf.uni-lj.si

\begin{abstract}
An in vitro study was conducted to investigate the effects of soybean meal (SBM) treated with two commercially available quebracho (QUE) and chestnut wood (CWE) extracts, at three different concentrations $(15,30$ and $60 \mathrm{~g} / \mathrm{kg} \mathrm{SBM})$ on the extent and rate of gas and short-chain fatty acid (SCFA) production. During the incubation, the gas production was measured at regular intervals from 0 to $48 \mathrm{~h}$ and the data were fitted with the Gompertz model to model gas production dynamics. After $24 \mathrm{~h}$ volumes of two syringes per substrate were analysed for individual SCFA contents. Treatment of SBM with CWE and QUE at the lowest concentration significantly increased $(P<0.05)$ gas production at $24 \mathrm{~h}$ of incubation (Gas24) and total SCFA production, but did not affect the proportions of individual SCFA. At higher concentrations (30 and $60 \mathrm{~g} / \mathrm{kg} \mathrm{SBM}$ ), only the CWE significantly decreased $(P<0.05)$ Gas24, while both tannins significantly decreased $(P<0.05)$ the maximum fermentation rate. Both higher concentrations of CWE and QUE also did not affect total SCFA production, yet CWE significantly increased $(P<0.05)$ the proportion of acetic acid, while QUE tannins did not affect the proportions of individual SCFA. Obtained results suggest that the low doses of QUE and CWE have a stimulating effect on rumen microorganisms, enhancing the extent and rate of fermentation, while higher doses of CWE and QUE decrease the rate of fermentation; however, only CWE affects the fermentation pattern of rumen microorganisms by changing the proportions of individual SCFA.
\end{abstract}

\section{Introduction}

Bioactive compounds have been extensively studied as a strategy to manipulate rumen fermentation in pursuit of an improvement of domestic ruminant productivity. Among them, a lot of attention was given to tannins, which are a complex group of polyphenolic compounds occurring in a wide range of plant species commonly consumed by ruminants (Mueller-Harvey, 2006). They are classified as condensed and hydrolysable tannins and both groups are extremely widespread having both beneficial and detrimental effects. The most commonly used representatives of condensed tannins are quebracho tannins, while those of hydrolysable tannins are chestnut tannins (Frutos et al., 2000). Recent studies on tannins point out the importance of considering their dosage-dependent effect on nutrient fermentation and digestibility; while moderate concentrations can exert beneficial effects on protein metabolism in ruminants, higher dietary concentrations can depress digestive efficiency and thus also animal productivity (Hervás et al., 2003; Lavrenčič and Levart, 2021). 
One of the key goals in ruminant nutrition is to optimize the efficiency of protein utilization, reducing the rate and the extent of rumen degradation of protein-rich feeds. The general idea of the effect of the tannin on rumen degradation, being more evident for protein than for other components, has been attributed to the greater hydrogen bond affinity of the tannin molecule with the carbonyl oxygen of the peptide group (Mueller-Harvey, 2006). The effect of tannins on reducing fibre digestion has been regarded as a secondary anti-nutritional effect in comparison with protein digestion. According to McSweeney et al. (2001), tannins could reduce fibre digestion by complexing with carbohydrates and preventing microbial attachment and degradation, or by directly inhibiting fibrolytic microorganisms and their enzymes. During the digestion of nutrients in the rumen, the majority of gas and short-chain fatty acids derived from the fermentation of fermentable dietary carbohydrates as the fermentation of protein (casein) produced only $32 \%$ of gas in comparison with carbohydrates (Cone and van Gelder, 1999).

Khazaal et al. (1994) concluded that the in vitro gas production technique appeared to be better suited to the assessment of phenolic-related anti-nutritive effects of feeds than in situ (nylon bag) methods. The in vitro gas production technique, although it is recognised not to be truly representative of biological systems, allows determining the effects of physical binding of tannins to the substrate (e.g., protein and/or carbohydrates) along with other effects such as toxicity to microbes or binding to their enzymes. So the results obtained from this in vitro technique, permit some conclusions to be drawn on the effect of the supplements, such as tannins, on the rumen fermentation.

In a recently published paper by Lavrenčič and Levart (2021), the chestnut wood extract containing mainly hydrolysable tannins reduced the in vitro dry matter (DM) and crude protein (CP) degradability more effectively than quebracho wood extract (condensed tannins). The present experiment aims to determine if the effects of decreased in vitro $\mathrm{DM}$ and CP degradability of soybean meal treated with tannins are reflected also in alteration of rumen microbial activity measured by in vitro gas production and short-chain fatty acid production.

\section{Material and methods}

\section{Soybean meal, tannin sources and preparation of soybean meal-tannin mixtures}

Soybean meal (SBM) and dry commercial water extracts of sweet chestnut (CWE; Castanea sativa L.) and quebracho wood(QUE; Shinopsis spp.) were used. Both extracts were provided by the company Tanin Sevnica (Sevnica, Slovenia). The treatments of SBM with tannin extracts were described by Lavrenčič and Levart (2021). In brief, SBM (500 g) was weighed in 3-1 plastic containers and 7.5, 15 and $30 \mathrm{~g}(15,30$ and $60 \mathrm{~g}$ of tannin extract per $\mathrm{kg}$ of SBM) of one of the tannin sources (e.g., CWE or QUE) were added. The SBM and tannin extracts were homogenized until an even colour was obtained. Tap water was added progressively to completely cover the mixture and the mass was stirred until a homogenous brownish paste was obtained. The stirring was continued for another 5 to 10 min until all water was incorporated. The mixtures were then left to stand for $12 \mathrm{~h}$ (overnight) at ambient temperature to allow tannins and protein to react. The mixtures were then dried and ground. The temperature during the drying was set to $70{ }^{\circ} \mathrm{C}$ for the first $24 \mathrm{~h}$ and lowered to $50^{\circ} \mathrm{C}$ for the remaining time (approx. 2 days) until the constant weight of the mixture was obtained. To remove the lumps, the dried mass was ground into fine particles (approx. 1-mm) and stored in dark at ambient temperature until analysed. The same procedure was also performed for SBM without added tannins (control; CON). All substrate preparations for each tannin treatment and the control were made in duplicate. The composition of substrates is given in Table 1 .

Table 1. Chemical composition of soybean meal treated with chestnut (CWE) and quebracho (QUE) wood extracts, g/kg DM

\begin{tabular}{|c|c|c|c|c|c|c|c|}
\hline \multirow{3}{*}{ Indices } & \multicolumn{7}{|c|}{ Treatment $^{1}$} \\
\hline & \multirow{2}{*}{ CON } & \multicolumn{3}{|l|}{ CWE } & \multicolumn{3}{|l|}{ QUE } \\
\hline & & 15 & 30 & 60 & 15 & 30 & 60 \\
\hline $\mathrm{DM}, \mathrm{g} / \mathrm{kg}$ & 923 & 911 & 867 & 851 & 912 & 933 & 920 \\
\hline $\mathrm{CP}$ & 567 & 524 & 525 & 501 & 522 & 533 & 524 \\
\hline EE & 11 & 14 & 14 & 14 & 11 & 12 & 13 \\
\hline Ash & 78 & 76 & 74 & 72 & 75 & 74 & 76 \\
\hline NDF & 111 & 102 & 112 & 104 & 104 & 133 & 121 \\
\hline NFC & 233 & 284 & 275 & 309 & 288 & 248 & 266 \\
\hline
\end{tabular}

1 treatments: CON - control, CWE and QUE - both extracts were added at a dose of 15,30 and $60 \mathrm{~g} / \mathrm{kg}$ of substrate; DM - dry matter, $\mathrm{CP}$ - crude protein, EE - ether extract, ash - crude ash, NDF - neutral detergent fibre, NFC - non-fibre carbohydrates (1000 - (CP + EE + Ash + NDF))

\section{Animals and diets}

Sheep rumen fluid was derived from two mature castrated Jezersko Solčavska $\times$ Romanovska rams (Ovis aries) weighing on average $70 \mathrm{~kg}$ and fitted with permanent rumen cannula. They received a daily ration containing average quality hay ad libitum (they consumed approx. $1.5 \mathrm{~kg}$ ) and $0.25 \mathrm{~kg}$ of pelleted commercial compound feed 
daily (160 g CP/kg), supplemented with mineral and vitamin mix $(0.025 \mathrm{~kg})$ once a day. The diet composition was calculated according to the German metabolizable energy (ME) and utilizable protein requirements (nXP; DLG, 1997) to cover the energy and protein requirements for maintenance and to balance the energy-to-protein ratio in the rumen.

\section{In vitro gas production}

In vitro gas production was determined according to the procedure described by Menke and Steingass (1988). In each of two runs (batches), each duplicate of SBM-tannin extract mixture and control $(207 \pm$ $0.5 \mathrm{mg} /$ syringe) was anaerobically incubated in four $100-\mathrm{ml}$ glass syringes containing $30 \mathrm{ml}$ of buffered rumen fluid. The production of gas resulting from microbial fermentation was measured manually after $0,2,4,6,8,10,12,24,36$ and $48 \mathrm{~h}$. The syringes were emptied only if the volume of gas produced in the first $36 \mathrm{~h}$ exceeded $80 \mathrm{ml}$ of the total syringe volume. After $24 \mathrm{~h}$, two of the four syringes of each SBM-tannin extract mixture duplicate were withdrawn, their contents were poured into $50-\mathrm{ml}$ plastic tubes and kept in a freezer at $-20{ }^{\circ} \mathrm{C}$ until short-chain fatty acids (SCFA) analysis. In each run, four syringes with blank samples (two for gas production and two for SCFA determination) and two syringes with standard hay were also incubated. At the end of the trial, the means and standard deviation of standard hay gas yields within and between runs were calculated. The coefficient of variation within and between runs was always lower than $4 \%$; therefore, no corrections of gas production of feed samples were made.

\section{Short-chain fatty acids}

The extracts for the SCFA were prepared according to the modified method of Holdeman et al. (1977). Short-chain fatty acids were analysed using a gas chromatograph (Hewlett Packard 5890 A; Hewlett Packard, Bellefonte, PA, USA) equipped with a split/splitless injector and flame ionization detector (FID). For the SCFA separation, a $30-\mathrm{m}$ $\mathrm{Nukol}^{\mathrm{TM}}$, fused silica capillary column (Supelco, Bellefonte, PA, USA) was used.

\section{Calculations and statistical analyses}

The calculation of gas production kinetic parameters was performed according to Lavrenčič et al. (1997). In brief, the net volume of gas produced at each incubation time was calculated as the difference between the total volume of gas produced and the volume of gas produced from the blank sam- ple at each time of incubation. Net volumes at each time of incubation were adjusted afterwards to $1 \mathrm{~g}$ of substrate $\mathrm{DM}$. The obtained in vitro gas production data were then fitted with the Gompertz model (Lavrenčič et al., 1997):

$$
Y_{t}=B \times e^{-C \times e^{-A t}},
$$

where: $Y_{t}-$ gas produced $(\mathrm{ml} / \mathrm{g} \mathrm{DM})$ at the time ' $\mathrm{t}$ '; 'B' - asymptotic amount of produced gas (total potential gas production $(\mathrm{ml} / \mathrm{g} \mathrm{DM})$ ); 'C' - specific gas production rate as affected by ' $t$ ', governed by a constant ' $A$ ', describing the decay in specific gas production rate (caused by the diminishing growth rate of microorganisms and increasing substrate limitation as reflected in gas production); and ' $\mathrm{t}$ ' - time (h).

Parameter values and curve fitting were estimated by the Marquardt compromise for a non-linear regression method (PROC NLIN; SAS Software ver. 9.4; SAS Institute, Cary, NC, USA). Amounts of gas produced in $24 \mathrm{~h}$ were calculated by inserting this fixed time $(24 \mathrm{~h})$ in the Gompertz model. The variation of gas production rates was obtained from the first derivative of the Gompertz model concerning the time of incubation. Times of maximum fermentation rates (TMFR) were calculated by setting the second derivative of the Gompertz model to zero (0) and solving for ' $t$ '. Maximum fermentation rates (MFR) were then calculated using the appropriate value of TMFR in the first derivative of the Gompertz equation. The net amount of total and individual SCFA produced after $24 \mathrm{~h}$ of incubation was calculated by subtraction of the average amount of total and individual SCFA produced from blank samples after $24 \mathrm{~h}$ of incubation and by adjusting the total and individual SCFA production to $1 \mathrm{~g}$ of substrate DM.

Data were analysed with the mixed model procedure (SAS Software ver. 9.4; SAS Institute, Cary, NC, USA). The average values within each tannin mixture duplicated within each run were considered as statistical replicates. Tannin treatment means for each level were compared against the CON using the least square mean linear hypothesis (LSMEANS/DIFF) with the Dunnett adjustment. Orthogonal polynomial contrasts were used to determine linear and quadratic responses to the level of tannin $(0,15,30$ and $60 \mathrm{~g}$ of tannin/ $\mathrm{kg}$ of SBM) within each tannin source and matrix coefficients were generated by using the PROC IML of SAS Software ver. 9.4 (SAS Institute, Cary, NC, USA) for unequally spaced contrasts. Statistical significance was declared at $P<0.05$. 


\section{Results}

The estimated parameters of gas production are presented in Table 2. All estimated gas production parameters were affected by experimental treatments $(P<0.001)$, showing linear and quadratic responses for both tannin extracts $(P<0.001)$, except for the parameter ' $A$ ' for which the QUE showed only a linear response. The lowest dosages of CWE and QUE $(15 \mathrm{~g} / \mathrm{kg} \mathrm{SBM})$ increased $(P<0.05)$ total potential gas production (parameter 'B') by about 11 and $9 \%$, respectively, while only the highest dosage of CWE $(60 \mathrm{~g} / \mathrm{kg} \mathrm{SBM})$ decreased the ' $\mathrm{B}$ ' $(P<0.05)$ by about $9 \%$. On contrary, in comparison with CON, all dosages of both tannin extract decreased the specific gas production rate (parameter

Table 2. Effects of soybean meal (SBM) treatment with chestnut (CWE) and quebracho (QUE) wood extracts on estimated parameters of in vitro gas production

\begin{tabular}{cclll}
\hline Indices & $\begin{array}{l}\text { Tannin extract, } \\
\text { g/kg SBM }\end{array}$ & $\begin{array}{l}\mathrm{B}, \\
\mathrm{m} / \mathrm{g} \text { DM }\end{array}$ & $\mathrm{C}$ & $\mathrm{A}$ \\
\hline $\begin{array}{c}\text { Treatment } \\
\text { CON }\end{array}$ & 0 & 217 & 2.67 & 0.139 \\
$\mathrm{CWE}$ & 15 & $240^{*}$ & $2.26^{*}$ & 0.135 \\
& 30 & 219 & $2.13^{*}$ & $0.101^{*}$ \\
& 60 & $198^{*}$ & $2.14^{*}$ & $0.116^{*}$ \\
QUE & 15 & $237^{*}$ & $2.39^{*}$ & 0.150 \\
& 30 & 226 & $2.32^{*}$ & 0.126 \\
& 60 & 210 & $2.27^{*}$ & $0.117^{*}$ \\
RMSE & & 6.8 & 0.072 & 0.0080 \\
P-value & & & & \\
Trt & & $<0.001$ & $<0.001$ & $<0.001$ \\
CWE & $\mathrm{L}$ & $<0.001$ & $<0.001$ & $<0.001$ \\
& $\mathrm{Q}$ & $<0.001$ & $<0.001$ & $<0.001$ \\
QUE & $\mathrm{L}$ & 0.007 & $<0.001$ & $<0.001$ \\
& $\mathrm{Q}$ & $<0.001$ & $<0.001$ & 0.288 \\
\hline
\end{tabular}

1 treatments: CON - control, CWE and QUE - both extracts were added at a dose of 15,30 and $60 \mathrm{~g} / \mathrm{kg}$ of substrate; B - total potential gas production, DM - dry matter; $\mathrm{C}$ - specific gas production rate, governand ed by parameter A - constant factor of microbial (in) efficiency; RMSE - residual mean square error; $P$-values for Trt - treatments and orthogonal contrasts for $L$ - linear and $Q$ - quadratic effects; * - means within a column are significantly different from the $\mathrm{CON}$ at $P<0.05$

' $\mathrm{C}$ '). The greatest decreases in parameter ' $\mathrm{C}$ ' were determined for the middle and highest dosages of CWE by about $20 \%$. The middle and the highest dosages of CWE decreased $(P<0.05)$ the parameter 'A' by about 27 and $17 \%$, respectively, while only the highest dosage of QUE affected $(P<0.05)$ the parameter ' $A$ ' by about $16 \%$.

The effects of SBM treated with increasing amounts of tannin extracts on calculated parameters of gas production are presented in Table 3.
All calculated gas production parameters were affected by experimental treatments $(P<0.001)$. Treatment of SBM with CWE extract showed linear and quadratic responses $(P<0.05)$ for Gas24, while for MFR there was only a linear response $(P<0.001)$ and a tendency for a quadratic response $(P=0.057)$. CWE treatment did not show either linear or quadratic responses for TMFR. Similarly, when SBM was treated with QUE the linear and quadratic responses $(P<0.01)$ were shown for MFR and Gas24, while for TMFR only quadratic response was stated $(P<0.001)$.

Table 3. Effects of soybean meal (SBM) treatment with chestnut (CWE) and quebracho (QUE) wood extracts on calculated parameters of gas production

\begin{tabular}{ccccc}
\hline Indices & $\begin{array}{l}\text { Tannin extract, } \\
\mathrm{g} / \mathrm{kg} \mathrm{SBM}\end{array}$ & $\begin{array}{l}\text { MFR, } \\
\mathrm{ml} / \mathrm{h}\end{array}$ & $\begin{array}{l}\text { TMFR, } \\
\mathrm{h}\end{array}$ & $\begin{array}{l}\text { Gas24, } \\
\mathrm{ml} / \mathrm{g} \text { DM }\end{array}$ \\
\hline $\begin{array}{c}\text { Treatment }{ }^{1} \\
\text { Control }\end{array}$ & 0 & 11.1 & 7.0 & 197 \\
CWE & 15 & 11.9 & $6.0^{*}$ & $219^{*}$ \\
& 30 & $8.1^{*}$ & 7.5 & $181^{*}$ \\
& 60 & $8.4^{*}$ & 6.7 & $172^{*}$ \\
QUE & 15 & 13.1 & $5.8^{*}$ & $222^{*}$ \\
& 30 & $10.5^{*}$ & 6.7 & 202 \\
& 60 & $9.0^{*}$ & 7.0 & 183 \\
RMSE & & 0.64 & 0.35 & 7.5 \\
P-value & & & & \\
Trt & & $<0.001$ & $<0.001$ & $<0.001$ \\
CWE & $\mathrm{L}$ & $<0.001$ & 0.883 & $<0.001$ \\
& $\mathrm{Q}$ & 0.057 & 0.463 & 0.047 \\
QUE & $\mathrm{L}$ & $<0.001$ & 0.117 & $<0.001$ \\
& $\mathrm{Q}$ & 0.001 & $<0.001$ & $<0.001$ \\
\hline
\end{tabular}

${ }^{1}$ treatments: CON - control, CWE and QUE - both extracts were added at a dose of 15,30 and $60 \mathrm{~g} / \mathrm{kg}$ of substrate; MFR - maximum fermentation rate, TMFR - time of maximum fermentation rate, Gas24 - gas produced in $24 \mathrm{~h}$ of incubation, DM - dry matter, RMSE - residual mean square error; $P$-values for Trt - treatments and orthogonal contrasts for $L$ - linear and $Q$ - quadratic effects; ${ }^{*}$ - means within a column are significantly different from the $\mathrm{CON}$ at $P<0.05$

The lowest concentrations of CWE and QUE $(15 \mathrm{~g} / \mathrm{kg} \mathrm{SBM})$ did not affect the MFR, while higher concentrations (30 and $60 \mathrm{~g} / \mathrm{kg}$ SBM) decreased it by 37 and $32 \%$ for CWE and by 6 and $23 \%$ for QUE, respectively. On contrary, only the concentrations of CWE and QUE of $15 \mathrm{~g} / \mathrm{kg}$ SBM shortened the TMFR by about 17 and $21 \%$ for 60 and $72 \mathrm{~min}$, respectively.

Similarly to parameter ' $\mathrm{B}$ ', the Gas24 increased $(P<0.05)$ from $197 \mathrm{ml} / \mathrm{g} \mathrm{DM}$ to 219 (by $11 \%)$ and $222 \mathrm{ml} / \mathrm{g}$ DM (by 13\%) when the concentrations of CWE and QUE were $15 \mathrm{~g} / \mathrm{kg}$ SBM, respectively. With concentrations of CWE of 30 and $60 \mathrm{~g} / \mathrm{kg}$ SBM, the Gas 24 decreased by about 9 and 14\%, respectively. 
The effects of SBM treated with increasing amounts of tannin extracts on SCFA, proportions of individual SCFA and ratios between acetic acid (Ac) and propionic acid $(\mathrm{Pr})$ are presented in Table 4.

Table 4. Effects of soybean meal (SBM) treated with chestnut (CWE) and quebracho (QUE) wood extracts on short-chain fatty acid (SCFA) production (mmol/g DM) and proportions of individual SCFA (mmol/mmol SCFA)

\begin{tabular}{ccccccc}
\hline Indices & $\begin{array}{l}\text { Tannin extract, } \\
\text { g/kg SBM }\end{array}$ & SCFA & Ac & Pr & Bu & $\begin{array}{l}\text { Ac/Pr } \\
\text { ratio }\end{array}$ \\
\hline $\begin{array}{c}\text { Treatment } \\
\text { CON }\end{array}$ & 0 & 6.46 & 0.688 & 0.219 & 0.094 & 3.26 \\
CWE & 15 & $7.69^{*}$ & 0.673 & 0.230 & 0.097 & 2.94 \\
& 30 & 6.22 & $0.745^{*}$ & $0.184^{*}$ & $0.071^{*}$ & $4.17^{*}$ \\
& 60 & 6.28 & $0.760^{*}$ & $0.166^{*}$ & $0.073^{*}$ & $4.63^{*}$ \\
QUE & 15 & $9.09^{*}$ & 0.707 & 0.203 & 0.090 & 3.58 \\
& 30 & 7.51 & 0.681 & 0.220 & 0.099 & 3.13 \\
& 60 & 6.66 & 0.657 & 0.240 & 0.103 & 2.75 \\
RMSE & & 0.608 & 0.0190 & 0.0153 & 0.0062 & 0.351 \\
P-value & & & & & & \\
Trt & & $<0.001$ & $<0.001$ & $<0.001$ & $<0.001$ & $<0.001$ \\
CWE & $\mathrm{L}$ & 0.105 & $<0.001$ & $<0.001$ & $<0.001$ & $<0.001$ \\
& $\mathrm{Q}$ & 0.270 & 0.767 & 0.757 & 0.103 & 0.648 \\
QUE & $\mathrm{L}$ & 0.136 & 0.003 & 0.009 & 0.004 & 0.006 \\
& $\mathrm{Q}$ & $<0.001$ & 0.116 & 0.094 & 0.502 & 0.177 \\
\hline
\end{tabular}

${ }^{1}$ treatments: CON - control, CWE and QUE - both extracts were added at a dose of 15,30 and $60 \mathrm{~g} / \mathrm{kg}$ of substrate; DM - dry matter; $\mathrm{Ac}$ - acetic acid, $\mathrm{Pr}$ - propionic acid, Bu - butyric acid; RMSE - residual mean square error; $P$-values for Trt - treatments and orthogonal contrasts for $L$ - linear and $Q$ - quadratic effects; ${ }^{*}$ - means within a column are significantly different from the $\mathrm{CON}$ at $P<0.05$

Equally to estimated and calculated parameters of gas production, the SCFA production and proportions of individual SCFA were also affected by experimental treatments $(P<0.001)$. The treatment of SBM with QUE showed only a quadratic response $(P<0.001)$ for SCFA produced in $24 \mathrm{~h}$ of incubation, while there was no response from CWE treatment on SCFA production. CWE and QUE treatments showed only linear responses on proportion of $\mathrm{Ac}, \mathrm{Pr}$ and butyric acid $(\mathrm{Bu})$ and on the ratio between $\mathrm{Ac}$ and $\mathrm{Pr}$ $(P<0.05)$, while QUE treatment showed a tendency of quadratic response $(P=0.094)$ for the proportion of Pr. Only the lowest concentrations of CWE and QUE $(15 \mathrm{~g} / \mathrm{kg}$ SBM $)$ affected $(P<0.05)$ the SCFA production which increased by about 19 and $41 \%$, respectively. The Ac proportions increased $(P<0.05)$ by 8 and $10 \%$ when SBM was treated with 30 and $60 \mathrm{~g}$ of CWE, while QUE treatment did not affect the proportion of Ac. The proportions of $\mathrm{Pr}$ and $\mathrm{Bu}$ decreased $(P<0.05)$ by 19 and $32 \%$ and by 32 and $27 \%$ when the SBM was treated with 30 and $60 \mathrm{~g}$ of CWE, respectively, but remained unchanged when treated with QUE. The changes in the content of Ac and $\mathrm{Pr}$ affected $(P<0.05)$ also the ratios between Ac and Pr from 3.26 in CON to 4.17 and 4.63 when SBM was treated with 30 and $60 \mathrm{~g}$ of CWE, respectively; but there was no difference when SBM was treated with QUE.

\section{Discussion}

The results of the in vitro gas production obtained in this study followed a slightly different pattern than those on in vitro DM rumen degradation (ivDMDeg) of QUE- and CWE-treated SBM (Lavrenčič and Levart, 2021). The lowest concentration of CWE (15 g/ $\mathrm{kg}$ SBM) increased the cumulative gas production (parameter ' $\mathrm{B}$ ') and Gas 24 but did not affect ivDMDeg (Lavrenčič and Levart, 2021). On contrary, the lowest concentration of QUE increased not only cumulative gas production and Gas24 but also ivDMDeg (Lavrenčič and Levart, 2021). Hassanat and Benchaar (2013) and Castro-Montoya et al. (2018) found that concentrations of QUE greater than 20 and up to $30 \mathrm{~g} / \mathrm{kg}$ of diet DM, respectively, decreased linearly the cumulative gas production, while in our experiment equal or greater concentrations of QUE did not affect the cumulative gas production and Gas24 from SBM. Our results are also in agreement with observations of El-Waziry et al. (2007), who treated SBM with 1, 2 and 3\% QUE. In our study, only the concentrations of CWE equal or greater than $30 \mathrm{~g}$ of CWE $/ \mathrm{kg}$ SBM significantly decreased Gas 24 but only the highest concentration decreased the cumulative gas production. In contrast, Hassanat and Benchaar (2013) determined that the concentration as low as $20 \mathrm{~g} \mathrm{CWE} / \mathrm{kg}$ DM already decreased gas production, while El-Waziry et al. (2005) found that the potential gas production was reduced with $30 \mathrm{~g}$ of tannic acid (hydrolysable tannin)/kg SBM but not with lower concentrations. Castro-Montoya et al. (2018) assumed that the decrease in cumulative gas production (and most probably also Gas24) could be the consequence of the declined availability of fermentable nutrients due to the nonfermentable tannin extract addition. In our experiment, only the CWE affected the cumulative gas production and Gas24; however, the concentrations of CWE were always lower than the decline in gas production, suggesting that the decrease in gas production is also the result of the tannin actions. The increase in gas production by the lowest doses of CWE and QUE suggests that the activity of rumen microorganisms is stimulated by the presence of tannins. The inefficiency of higher CWE and QUE concen- 
trations suggests that the tannins may form linkages mainly to proteins non affecting fermentation of prevalent fermentative substrates such as carbohydrates or, as suggested by Jones et al. (1994), that some of the rumen microbes can tolerate relatively high concentrations of both hydrolysable and condensed tannins. Adaptive strategies of microorganisms could involve the creation of thick glycocalyx or glycoprotein that has a high binding affinity for tannins as well as the tendency to form glycocalyx-enclosed microcolonies (McSweeney et al., 2001). Higher concentrations of tannin extracts decreased the gas production (cumulative and Gas24) and rates of fermentation (MFR). These findings are in agreement with those of Hassanat and Benchaar (2013), who reported that negative effects of CWE and QUE on fermentation started to appear at a concentration of $50 \mathrm{~g} / \mathrm{kg} \mathrm{DM}$ and those of Pellikaan et al. (2011) who found that $100 \mathrm{~g}$ of QUE $/ \mathrm{kg}$ of lucerne hay reduced cumulative gas production, while CWE added in the same concentration did not have any effect. It is possible that the chemical composition of the tannin extracts used in our experiment differs considerably from those reported in other papers and that in other papers the tannin extracts were simply added to the substrate, while in our experiment the substrate was treated by soaking the substrate-tannin extract mix with water. Furthermore, Hervás et al. (2003) reported a decrease in gas production and rates of fermentation only when lucerne hay was incubated but not when barley straw was incubated in the presence of QUE. They suggested that the suppressive effect of QUE could be a result of a reduction in the attachment of microbes to feed particles and/or a specific inhibition of rumen degradation through inhibition of microorganism growth and their enzymes. However, the substrates used by Hervás et al. (2003) differed also in the protein contents. It was already noted that tannins preferentially binds to proteins suggesting that this could be a cause of a reduced extent and rate of substrate fermentation.

The parameter ' $A$ ' (constant factor of microbial (in)efficiency) was decreased when CWE was used at concentrations higher than $30 \mathrm{~g} / \mathrm{kg}$ SBM or when QUE was added at a dose of $60 \mathrm{~g} / \mathrm{kg}$ $\mathrm{SBM}$. On the other hand, parameter ' $\mathrm{C}$ ' (specific rate of fermentation) decreased for both examined tannin extracts regadless of dose. The decreasing values of parameters ' $C$ ' and ' $A$ ' with higher concentrations of tannin extracts change the pattern of fermentation and thus also the parameters MFR and TMFR, which generally decreased and prolonged, respectively. Increased MFR and shorter TMFR at the lowest concentrations of both tannin extracts $(15 \mathrm{~g} / \mathrm{kg} \mathrm{SBM})$ support the hypothesis that stressed rumen microorganisms increase their activity to alleviate the negative effects of tannins. Another possible explanation was given by Frutos et al. (2000), who claimed that microbes adapt to the action of tannins and other plant secondary metabolites by increasing their tolerance to those compounds through changes in the microbial population. However, Frutos et al. (2000) and Mueller-Harvey (2006) noted that condensed tannins are not degraded in the rumen and a long-term feeding of QUE should not lead to adaptation of rumen microbial populations to it. In contrast, hydrolysable tannins are degraded in the rumen, releasing the sugar and phenolic components, which could lead to adaptive actions of rumen microorganisms.

The production of SCFA followed the same pattern as cumulative gas production (and also Gas 24 and MFR) being higher than control when low doses $(15 \mathrm{~g} / \mathrm{kg} \mathrm{SBM})$ of tannin extracts were used but not different from control when higher doses of tannin extracts were added. These results are following the suggestion given previously that the lowest doses of CWE and QUE stimulated the activity of rumen microorganisms. Contrary, Castro-Montoya et al. (2018) and El-Waziry et al. (2007) noted that the total SCFA production was decreased already at concentrations of QUE higher and equal to $15 \mathrm{~g} / \mathrm{kg}$. However, Hassanat and Benchar (2013) reported that the concentrations of CWE and QUE have to be higher than $50 \mathrm{~g} / \mathrm{kg}$ diet DM to decrease SCFA production, while Pellikaan et al. (2011) reported that only QUE but not CWE at $100 \mathrm{~g} / \mathrm{kg}$ decreased total SCFA production. El-Waziry et al. (2005) observed lower SCFA production from tannic acid-treated SBM already at a concentration of $10 \mathrm{~g} / \mathrm{kg} \mathrm{SBM}$. In the present study, the CWE and QUE had different effects on the proportions of individual fermentation acids. CWE increased the proportion of Ac and decreased the proportions of $\mathrm{Pr}$ and $\mathrm{Bu}$, widening the ratio between $\mathrm{Ac}$ and $\mathrm{Pr}$, as was reported also by Jayanegara et al. (2012) as a general effect of tannins. QUE did not affect the proportions of $\mathrm{Ac}, \mathrm{Pr}$ and $\mathrm{Bu}$, as was reported also by Pellikaan et al. (2011) and Hassanat and Benchaar (2013). On contrary to our results these authors did not observe the effects of CWE on the proportion of Pr. The present results suggest that CWE increased the degradation of fibre (e.g., cellulose, hemicelluloses and pectins), which ferments mainly to Ac, and decreased the fermentation of non-fibre carbohydrates (e.g., sugars and starch), which ferment mainly to Pr and $\mathrm{Bu}$. 
Similar results were obtained also by Díaz Carrasco et al. (2017) who found that the blend of CWE (1/3) and QUE (2/3) at $0.2 \%$ of diet DM increased the cellulolytic bacteria while inhibiting those microbial genera which have important roles in the fermentation of starch, hemicelluloses and pectins. In contrast to our results, Kos (2007) found that not only CWE but also QUE increased the proportions of $\mathrm{Ac}$ and $\mathrm{Bu}$ when pure cellulose was incubated, while $\mathrm{CWE}$ decreased the proportions of $\mathrm{Ac}$ and $\mathrm{Bu}$ and QUE did not affect the proportions of individual SCFA when pure potato starch was incubated. Variable effects of different tannins on SCFA production and proportions of individual SCFA confirm the assumptions obtained from the results of Martínez et al. (2006) that tannin activity depends not only on the type, structure and concentration of tannins used but also on the source of the substrate.

\section{Conclusions}

The impact of tannins on in vitro fermentation varied according to their type and concentration. At low concentrations, the gas production increased suggesting the stimulating effect of tannins on rumen microbe activities. The increasing concentrations of tannins resulted in the decline of gas production in $24 \mathrm{~h}$ of incubation (Gas24) which was more prominent with chestnut wood extract (CWE) than with quebracho (QUE) tannins. Not greatly affected total short-chain fatty acid (SCFA) production but changed proportions of individual SCFA suggest that shift in fermentation pattern towards acetate production occurred by treating soybean meal (SBM) with CWE but not with QUE. This in vitro study showed also that the decreasing effect of CWE on gas production, especially Gas 24 , starts at relatively low concentrations, while those of QUE at concentrations equal or even higher than $60 \mathrm{~g} / \mathrm{kg}$, suggesting that QUE has a lower affinity to form linkages with feed constituents and thus does not similarly affect rumen fermentation than the CWE. Further work is necessary to assess the possible relation between tannin abilities to modify rumen fermentation and microbial activity regarding different types and concentrations of tannins and also different substrates. Furthermore, the obtained results need to be confirmed also in in vivo studies.

\section{Conflict of interest}

The authors declare that there is no conflict of interest.

\section{References}

Castro-Montoya J., Westreicher-Kristen E., Henke A., Diaby M., Susenbeth A., Dickhoefer U., 2018. In vitro microbial protein synthesis, ruminal degradation and post-ruminal digestibility of crude protein of dairy rations containing Quebracho tannin extract. J. Anim. Physiol. Anim. Nutr. 102, e77-e86, https:// doi.org/10.1111/jpn.12704

Cone J.W., van Gelder A.H., 1999. Influence of protein fermentation on gas production profiles. Anim. Feed Sci. Technol. 76, 251-264, https://doi.org/10.1016/S0377-8401(98)00222-3

Díaz Carrasco J.M., Cabral C., Redondo L.M., Pin Viso N.D., Colombatto D., Farber M.D., Fernández Miyakawa M.E., 2017. Impact of chestnut and quebracho tannins on rumen microbiota of bovines. BioMed Res. Int. 2017, 9610810, https://doi.org/10.1155/2017/9610810

DLG (Deutsche Landwirtschafts-Gesellschaft), 1997. Feed Value Table for Ruminants. $7^{\text {th }}$ Revised and Extended Edition (in German: DLG Futterwerttabellen: Wiederkäuer). DLG-Verlag. Frankfurt (Germany)

El-Waziry A.M., Nasser M.E.A., Sallam S.M.A., 2005. Processing methods of soybean meal. 1. Effect of roasting and tannic acid treated-soybean meal on gas production and rumen fermentation in vitro. J. App. Sci. Res. 1, 313-320

El-Waziry A.M., Nasser M.E.A., Sallam S.M.A., Abdallah A.L., Bueno I.C.S., 2007. Processing methods of soybean meal. 2. Effect of autoclaving and quebracho tannin treated-soybean meal on gas production and rumen fermentation in vitro. J. App. Sci. Res. 3, 17-24

Frutos P., Hervás G., Giráldez F.J., Fernández Gutiérrez M., Mantecón Á.R., 2000. Digestive utilization of quebracho-treated soya bean meals in sheep. J. Agric. Sci. 134, 101-108, https://doi. org/10.1017/S0021859699007261

Hassanat F., Benchaar C., 2013. Assessment of the effect of condensed (acacia and quebracho) and hydrolysable (chestnut and valonea) tannins on rumen fermentation and methane production in vitro. J. Sci. Food Agric. 93, 332-339, https://doi.org/10.1002/jsfa.5763

Hervás G., Frutos P., Giráldez F.J., Mantecón Á.R., Álvarez Del Pino M.C., 2003. Effect of different doses of quebracho tannins extract on rumen fermentation in ewes. Anim. Feed Sci. Technol. 109, 65-78, https://doi.org/10.1016/S03778401(03)00208-6

Holdeman L.V., Cato E.P., Moore W.E.C., 1977. Ether extraction of volatile fatty acids. In: Anaerobe Laboratory Manual. $4^{\text {th }}$ Edition. Virginia Polytechnic Institute and State University. Blacksburg, VA (USA)

Jayanegara A., Leiber F., Kreuzer M., 2012. Meta-analysis of the relationship between dietary tannin level and methane formation in ruminants from in vivo and in vitro experiments. J. Anim. Physiol. Anim. Nutr. 96, 365-375, https://doi. org/10.1111/j.1439-0396.2011.01172.x

Jones G.A., McAllister T.A., Muir A.D., Cheng K.-J., 1994. Effects of sainfoin (Onobrychis viciifolia Scop.) condensed tannins on growth and proteolysis by four strains of ruminal bacteria. Appl. Environ. Microbiol. 60, 1374-1378, https://doi. org/10.1128/aem.60.4.1374-1378.1994

Khazaal K., Bosa J., Ørskov E.R., 1994. Assessment of phenolicsrelated antinutritive effects in Mediterranean browse: a comparison between the use of the two in vitro gas production technique with or without insoluble polyvinylpolypyrrolidone or nylon bag. Anim. Feed Sci. Technol. 49, 133-149, https://doi. org/10.1016/0377-8401(94)90087-6 
Kos T., 2007. Influence of tannins on volatile fatty acids and methane production in in vitro fermentation in rumen fluid. Graduation Thesis. University of Ljubljana. Ljubljana (Slovenia), pp. 66

Lavrenčič A., Levart A., 2021. In vitro dry matter and crude protein rumen degradation and abomasal digestibility of soybean meal treated with chestnut and quebracho wood extracts. Food Sci. Nutr. 9, 1034-1039, https://doi.org/10.1002/fsn3.2072

Lavrenčič A., Stefanon B., Susmel P., 1997. An evaluation of the Gompertz model in degradability studies of forage chemical components. Anim. Sci. 64, 423-431, https://doi.org/10.1017/ S1357729800016027

Martínez T.F., McAllister T.A., Wang Y., Reuter T., 2006. Effects of tannic acid and quebracho tannins on in vitro ruminal fermentation of wheat and corn grain. J. Sci. Food Agric. 86, 1244-1256, https://doi.org/10.1002/jsfa.2485
McSweeney C.S., Palmer B., McNeill D.M., Krause D.O., 2001. Microbial interactions with tannins: nutritional consequences for ruminants. Anim. Feed Sci. Technol. 91, 83-93, https://doi. org/10.1016/S0377-8401(01)00232-2

Menke K.H., Steingass H., 1988. Estimation of the energetic feed value obtained from chemical analysis and in vitro gas production using rumen fluid. Anim. Res. Develop. 28, 7-55

Mueller-Harvey I., 2006. Unravelling the conundrum of tannins in animal nutrition and health. J. Sci. Food Agric. 86, 2010-2037, https://doi.org/10.1002/jsfa.2577

Pellikaan W.F., Stringano E., Leenaars J., Bongers D.J.G.M., van Laar-van Schuppen S., Plant J., Mueller-Harvey I., 2011. Evaluating effects of tannins on extent and rate of in vitro gas and $\mathrm{CH}_{4}$ production using an automated pressure evaluation system (APES). Anim. Feed Sci. Technol. 166-167, 377-390, https://doi.org/10.1016/j.anifeedsci.2011.04.072 